\title{
Thyroid and your biography: how unexpressed thoughts and feelings can cause low thyroid ... with three case studies
}

Volume 5 Issue 4 - 2017

\section{Conceptual paper}

The thyroid represents the essential aspect of a human being. It is through our throat that we express our inner most strength of will, ability to follow our dreams and to share out inner most desires of the heart. It is the center of demonstrating our choice, When one's ability to speak up and to be heard has been shut down, blocked or belittled the throat and jaw become constricted causing a disruption of the flow of thyroid hormones, blood and other essential biological substances from and to the thyroid which influences metabolic rate, protein synthesis and intellectual development.

Yet it is not merely the disruption of what the thyroid gland secretes that is important, for thyroid imablance signifies an ongoing condition of systemic distress that sends other unhealthy inner pharmacy prescriptions to the endocrine and nervous sytems that exasperates the inbalance and predisposes an individual to many other biological and emotional illnesses.

Sadly thyroid dysfunction begins as early as birth for it is this area of the body, the lips, mouth and its direct connection to the throat which is the first attempt by a human being to reach out for the milk of the mother breast to satisfy its needs for nourishment to survive. Should this not be available or not given from an emotional present and devoted mother, a disconnection occurs with a resultant restriction in the body of the infant as it instinctually feels its life is threatened causing an innate fear within. It is any wonder that with the huge number of caesarean births and non nursing mothers that thyroid imbalances, TMJ, eating disorders and feeling of not being loved and inadequacy are so prominent in our society. And these are just the tip of the iceburg!

These case studies provide a window into a few of these dynamics and what we can do to reopen the natural flow of our mind ,heart and mouth to return balance and well being to that representation in our system that is intimately connected to these issues. Of course there many other issues of what person with an imbalanced thyroid condition may be dealing with as the underlying concern buried in the unconscious mind/body but these example should serve as a hopeful guide of what is possible when seeing the different levels of a human being as the condensation of the one substance of Life itself as the spiritual, mental, emotional and physical elements all working together in a integrated system.

\section{Nina's story}

Nina had heard about my successful work with hypo thyroidism while she was attending a special program for her son, Timothy called The Clearminded Children's Program. Her son had been diagnosed with ADHD and placed on Ritalin and she wanted to find another way to help him without medications. In the program I had mentioned how children are strongly influenced by their parents emotional and mental

\author{
Brian Sheen \\ American Integrative medicine practitioner, USA
}

Correspondence: Brian Sheen, American Integrative medicine practitioner, Healing Arts Center, 777 East Atlantic Ave Suite B-4, Delray Beach, Florida, USA, Tel 56I-212-7029, Email drbriansheen@yahoo.com

Received: October 24, 2016 | Published: February 17, 2017

states and how their parents unconscious projections often created an unhealthy atmosphere for their child which exasperated any existing imbalances already in their system. As I emphasized that it was the stability of mother that was most important. Nina realized that she was a mess and hadn't been there emotionally as a solid foundation since her divorce. She hadn't been able to work for the past two years.

At first Nina's goal was to create some personal stability for herself to give her son a strong foundation to stand upon. Yet after when she read an earlier version of this article she realized she might also be able to obtain even greater help as her doctor had suggested she have her thyroid gland removed as it was barely functioning despite giving her medications to do so. Her doctor was afraid it could become cancerous and so thought it was a safe caution to take.

Nina decided to join one of my group Deep Healing Workshops which I ran weekly. Her primary goal was to become more stable and balanced. Her secondary goal was to have the strength to return to the workforce. A third goal was to strengthen her existing romantic relationship. She listed as an "unrealistic" goal. She had returning the proper functioning of her thyroid.

I made it clear with Nina from the outset we would focus only on her primary goal as it was merely a six evening workshop consisting of about fourteen hours of transformational work. I told her that as her goals were so tied together, she might also experience some improvement in her other areas of interest.

As I do in all my Deep Healing Workshops I explain the four levels of consciousness and how they interact, body, emotions, mind and spirit (listen to Miracles through the Body CD Series for a more in-depth explanation). We spoke of how chronic holding patterns reduce blood and oxygen flow in our bodies and predispose it to many levels of weakness and illness (ischemia). Like having a hose which is watering a garden, when it is pinched and constricted, it causes a reduction in its water flow. I explained how our body acts in the same way from stress locked in its system from present time events and past traumas still held inside.

Nina was very open to all she was learning and quickly connected to the bioenergetics processes we used. She quickly recognized 
how she had chronically locked her jaw, tightened her throat, held her breath, tightened her chest, pulled in her hips and felt weak in the knees. The work she had done with her son in the Clearminded Children's Program already taught her ways to focus, relax, meditate and reach out more, but it wasn't designed for her to access her deeply repressed fears and anger which she buried deep inside her unconscious $\mathrm{mind} /$ body.

Nina worked hard each week doing special embodiment processes that had her connect to and break her unconscious pattern of how she unconsciously held on to anger, hatred and fear from her childhood. These feelings were beyond what she consciously believed was the cause; her miserable last marriage and traumatic divorce. It became clear as we accessed this rage that she had made such a poor choice for the first husband because of the trance she was still in from her childhood, trying to get Daddy to meet her needs for connection and containment while not protecting her from her mothers emotional outbursts due to her overly "social" drinking and inability to be there for her. She felt used by her mother to meet her mother's needs while her father was so busy working he wasn't able to protect her from the frustration and isolation she felt

Piles and piles of rage was released. For the first time she was able to voice what was locked inside without the fear of further punishment As she said during the process, just having these repressed feelings and thoughts heard and acknowledged by another was so freeing. Each week her face, posture and attitude softened more.

One of the principles of healing I stress is how we all must face and embrace the untreated aspects of pain and trauma repressed in our unconscious mind/body so it can be traced to its source and allowed to be replaced with a new healing energy. I stress how its not what you feel about something now which matters, as the years of coping mechanisms have set up so many defenses to avoid feeling what you felt back then, the ego will only minimize it or explain how you've already forgiven it and its nothing. Yet, as I point out, this is a popular defensive ego trick to not look within and live inside the head, afraid to go to the deeper levels of condensed emotion stuffed in different parts of the body. This is why I use embodiment work, purifying breath and bioenergetics to unlock these hidden levels which are the roots buried in the muscles, tissues, nerves and bone structure.

Each week Nina released and realigned enormous amounts of repressed emotion thought and action. To her credit she was ready, willing and able to take these steps as she was so sick and tired of being sick and tired! Throughout each workshop session we integrated many of the principles of forgiveness from A Course in Miracles connection to the space of Oneness from meditation and Deep Healing fundamentals. She occasionally attended these classes as well. In one enactment we did Nina was very resistant to face her previous boss and speak her mind until the dots were connected that showed she associated him with her father. She had developed a powerful Super Ego ideal never to speak back to her father as it would be a horrible sin punishable by God "Honor thy mother and thy father". Yet, with some encouragement we reevaluated that blanket injunction and reframed it that the best way to honor her mother and father was to honor her natural impulses inside. Perhaps it was this shift that put all the others in realignment and by the end of the workshop she had two of her four goals and felt stable, balanced and enjoying a healthier and happier relationship with her new husband. Two weeks after the workshop she told me she had just accepted an exciting new job. Six weeks later she was told by her doctor that he canceled the thyroid surgery as it was now completely in balance.
Nina's results were so remarkable because of the months of work she had done in The Clearminded Children's Program with her son. She became familiar with the paradigm of healing I used and held little resistance to embrace it and look within. Her motivation for helping her son was a powerful drive that kept her concentrated on her goals and I think the fear of surgery encouraged her to take the approach of - I might as well give it all I have as I have nothing to lose and so much to gain. Of course besides Nina her son was even a greater beneficiary in all these as well as her boyfriend - both who were very grateful for all the help she received.

\section{Cynthia's story}

Cynthia was upset when she first came into my office. She felt she was so out of touch with her body that she finally decided to explore the possibility that there was more to her thyroid condition than what was being diagnosed by her medical practitioner.

"It seems like I'm on a rollercoaster. Ten years ago I was diagnosed with hypothyroidism. I was tired, often depressed and very moody", she said with exasperation.

"These are common symptoms of an under active thyroid", I commented.

"Yes, I know this now, and for a number of years my synthyroid prescription seemed to help me have more energy. Even my hands and feet felt warmer. But, still I was very moody despite all the tests done and the medications tried. You name it and I've tried it.'

"It's excellent to see your conviction to be well. A determined mind is the most important ingredient in healing", I said.

"But that was before when my thyroid medication failed me. Apparently I had built up such a resistance over the years that even that medication failed to help me anymore."

"The body is a very complex system of organized intelligence that interacts with your emotional and mental states to seek a homeostasis. It seeks balance to ensure its own survival. Your brain has some 10 billion cells each with a potential of 20,000 connections operating at lightning speed in conjunction with your mind. It is not uncommon for your system to readjust itself to prevent a perceived artificial interference from damaging its natural immune and biological defenses," I explained.

"Exactly!" she said. "This is exactly what brings me here to you today. I realize there must be something deeper inside me that caused this to occur which is not merely of a physical nature. A friend of mine gave me Dr. Deepak Chopra's book, Quantum Healing where he speaks about the powerful mental mechanisms of consciousness that can be instrumental in healing many illnesses that have not fully responded to medication. When I passed by your office last week and saw your centers' sign 'Quantum Healing' I felt that this was some type of synchronicity. It was no coincidence that I had just been at my doctor that morning and he wanted to try me on a new combination of drugs including Zoloft."

I gently smiled at Cynthia "Yes, it is amazing how the universe can send us certain messages if we have our eyes open and are willing to listen to the signposts which surround us. I named my healing center after that very book because after thirty years of working with the mind-body connection for healing,. I have spent thirty-two years working and researching in this field and it seems at last the recognition of the power of the mind to heal itself and the body was at last acknowledged." 
"So where do we start?" she said.

"At the beginning of course!" I declared. In my many years of research on the interface of the endocrine system with the mind I have found there are three situations present in any illness. The three P's I call it. The first one is predisposition. This is an emotional and/or life situation which creates a non-optimal condition of living. When an individual lives in a household of this nature an underlying sense of fear, danger and guilt permeates the mind which causes it to get stuck in the stress mode often called a fight or flight reaction. This creates a continual strain on the body. As the lungs overwork, the immune system is weakened and harmful levels of cortisol and adrenaline are produced to create chemical imbalances. This is why we see such an epidemic of serotonin deficiencies today.

\section{Low thyroid and the precipitation of illness}

The second $\mathrm{P}$ behind any illness is precipitation. Our body-mind system for most of us is very resilient and can often overcome, in our earlier years, much physical and emotional abuse. Yet, over time as we age even the strongest are weakened and the resistant negative beliefs and decisions that were made in our lifetime due to the negative conditioning we had will finally bear its toxic front. One day a physical or emotional trauma occurs and this can precipitate an onslaught of system breakdowns that can bring cancer, heart disease, hypo or hyperthyroid conditions, colitis, irritable bowel syndrome, anxiety-panic disorders or any number of maladies into symptomatic consciousness. It is important to understand that whatever finally emerges did not just happen. These imbalances were in the mind/body system before the symptoms manifested. We all have a potential for cancer in our bodies. Yet it is through the systems' weakening by the trauma that the illness in waiting debuts.

By this time tears were rolling down Cynthia's face. "I know your $\mathrm{Ph} . \mathrm{D}$. is in clinical hypnotherapy and you specialized in psychoneuroimmunology, but are you a psychic too? I feel you're reading my mind and telling me all about my life without me saying a word. I've had a horrible childhood. My parents were always fighting and my father sexually abused me as a child. I always felt frightened to speak out about it as I thought my mother must have known but did nothing. Even when I tried to bury myself in outside activities I always had this terrible feeling inside me when I went back home. As a kid I always seemed to have stomach problems which my doctor told me was because I took life too seriously. Too seriously, my God, I was afraid to go to sleep at night in my bed. My stomach problems went away when I went off to college and things went pretty well. I dreaded the holidays for it meant going home but I learned to stuff my fears deeply inside. My parents eventually got divorced so it made me easier and my dad to never bother me again. But then I got married - my first. Things just got off on a bad foot and like my father, my new husband had a drinking problem that I was in full denial about. I tried the best I could but before long became too much and I started having trouble getting out of bed in the morning. When I went into my doctor he ran a lot of tests and told me although unusual at my age, my thyroid was very low and he started me on the various medications. Finally we found synthyroid was what worked best and we stuck with that up until recently. I divorced my first husband and remarried five years later to a really nice man. We get along pretty well most of the time but sometimes I feel like running for my life."

"This is the third P-Perpetuation. Buried deep in your unconscious mind are large amounts of traumas some painful, some threatening and others filled with loss or rekindling of old negative feelings and beliefs. Although you have some conscious awareness of what these stem from an undeniable axiom of healing is - you're never upset for the reason you think! When the core issues have been taken from the unconscious portion of your mind and brought into consciousness, the hidden nature of the real seed of discontent will be removed. The key is awareness of what is buried beneath your current consciousness. It's like having a garden filled with weeds, you can quickly create an appearance of a well groomed lawn just by mowing it, yet after a few days the weeds will once again pop up as the underling roots are still there. Unless you dig beneath the soil (your conscious mind) and pull the roots completely out (the unconscious traumas you have forgotten) the weeds (your negative symptoms) will return. This is why in 1954 the AMA authorized the use of hypnosis as an approved modality of healing. As helpful as medications and talk therapy have been over the years, it was often discovered that over time the symptoms returned or found a different way to demonstrate themselves. Instead of appearing as one form of dysfunction (an uncontrollable anger, ulcers, colitis) it now emerges as an apparently different symptom (depression, or hypothyroid). Without going deeply within to bypass the conscious gatekeeper that's afraid to examine the painful memories it has shut itself off from - only temporary releases are possible."

"You're both exciting and frightening me at the same time" Cynthia said, "I am scared to think there is more trauma than I know about. I don't want to re-experience any more pain then I already have nor do I want to give up control of my mind to someone else. Isn't there another way?" she nervously related.

"Your concerns are understandable and I assure you that many people I have worked with have felt the same way before we began. Fortunately it is not necessary to have to experience any of the pain you had before - ever. That's the benefit of working with today's modern approaches to hypnotherapy. Let's face it, once was enough! And let's acknowledge you survived it or you wouldn't be sitting here before me today. All hypnosis is self-hypnosis, which really is just a deeply relaxed state of comfort and focused mind. You are aware of exactly what is happening at all times and can return to your regular state of mind anytime you like. With different modes of hypnotherapy like Neurolinguistic Programming (NLP) or Core Transformation, there isn't even any induction done. Every client I have worked with over the years has said how much easier it was then they ever thought and how peaceful and relaxed they felt afterwards."

"The first thing we'll do before we touch upon any deep issues is to spend a session getting you comfortable with the different types of processes I use so you can feel at ease. This allows me to discover which techniques will work best for you."

\section{"I'm ready", she exclaimed. "Let's get the show on the road."}

Over the next 16 weeks we met 24times for sessions - a total of 40hours in all. Each week we incorporated a different approach depending upon what was presenting itself into her life. The mind is an amazing powerful instrument with a self-protecting mechanism. It only permits those issues, which the individual is ready to access to come into existence.

Within four weeks of working with Cynthia she communicated to me how much better she felt and she really could see "the forest through the trees."

In one portion of our work we uncovered a dozen or more conditioned beliefs that she had learned in her early childhood from her parents that were sabotaging her relationships causing her to make unreasonable demands on her partner to protect and defend her insecurities. These were quickly replaced by new beliefs that were 
healthy and based on the knowledge she had gained over the many years of her life experience and study. As mentioned in more detail in 'Kathy's story' below this is called Miracle Re-Patterning.

In another portion of our regression work we discovered forgotten memories in her first three years of life that left such a deep impression we actually saw facial shifts in her body that thinned at her cheek line and lifted her head in a renewed feeling of self confidence. The actual incidences of abuse despite the years of talking about them could never clear as they gained their staying power from earlier events of observing others being abused that caused her to hold on to her pain for "protection. Twice during regressions she came upon unexplainable images and experiences that she felt were past life memories. This brought her much new clarity of the life lessons she was "asked" to learn and why it was she had the parents she did. Each time although still uncertain if real or not she had tremendous releases of negative energies and was incredibly vibrant in her day to day activities. I used some Breath Purification, Core Transformation and NLP to integrate these changes.

Cynthia was very determined not only to heal but also to learn how to think, feel and act in new ways that weren't dependent on what behaviors she had modeled from her parents. Each week she came to meditation class to learn how to relax and learn a sense of detachment from her previous way of thinking as well as learning about her inner spiritual nature. She also regularly attended a class I facilitated called A Course In Miracles. As she told me, it gave her so many tools to deal with any ongoing situations she now encountered, that instead of piling up resentment and unresolved grievances, she now felt peaceful and happy most of the time.

After seven weeks she noticed that she was no longer lethargic or depressed and decided to set an appointment with her medical doctor to have her thyroid retested. Cynthia returned with her physicians test results in week 9 and told me how amazed her doctor was that her thyroid now operated at near maximum efficiency.

After 15 weeks, Cynthia was tested again. Her thyroid was now completely normal. Moreover Cynthia completely renewed the joy in her marriage to such a noticeable point her and her husband acted like newlyweds when they were together. She also found that her relationship with her two grown boys and her parents were greatly improved and was she was happy to be around them.

Cynthia was a new person and had regained her inner most Beingness. Her creativity also began to flourish as she renewed her interests in painting and music which she had abandoned twenty years earlier. Cynthia was having fun as a daily part of each day. The glow upon her face and warmth she radiated were clear indications of a happy healthy thyroid and mental mind self.

\section{Kathy's story}

Kathy had read the original article about Cynthia and living nearby my center in Delray Beach Florida asked if she could come in and meet with me. She was very excited as she felt the case of Cynthia was very similar to her own and so felt great hope she could finally overcome her hyperthyroidism diagnosed as Graves disease.

"I'm tired all the time," she said, "I don't want to exercise and I overeat. I'm filled with unresolved anger and feel worthless and depressed. My attitude is negative too much of the time and it seems I have a non-stop conflict with my husband that is getting worse. We don't agree on anything. I seem to drag things on for days and can't let go! I've tried many different combinations of medications and hormone therapy and nothing seems to work. I have even tried acupuncture and Body talk to no avail."

“These symptoms are common," I informed her. "When you are out of balance in your body it is a reflection of a deeper imbalance in your emotions and thus mind. You are carrying around many areas of unexpressed resentment, unresolved grievances from the past and repressing your natural life-force. The focus of our work together is to discover what triggers these symptoms and trace them back to the initial sensitizing events that have embedded them in your unconscious mind as a hidden program you function by. Let's review your history by making a timeline of the significant events in your life and create a picture of your inner consciousness that lurks below the surface."

At this point I spent the next two sessions developing Kathy's timeline and doing a variety of interventions as we went. The overview of Kathy's life was similar in content to what I had seen with many cases mentioning these same emotional and biological difficulties although with some extreme examples. She ran away from home as at 13 to live with her father as her parents divorced when she was 4 . Kathy and her mom constantly moved and she felt very unstable and disoriented. Her mom often had whipped her with a belt often and Kathy would dream of her revenge someday. She was so filled with anger and hatred towards her mom she had not visited her in 20years and despised all communications with her. It was as if she was still the victim child and couldn't get away.

Later when she moved in with her father he committed incest with her and it was a miracle she didn't take her own life. To top things off she later learned her parents had never even married so she felt as if salt was now rubbed into her wounds and she was choked with disgust.

During these disclosures we would focus on specialized techniques I developed called Miracle Re-patterning. These are processes I developed that incorporate the principles of A Course in Miracles with Meta NLP (Neurolinguistic Programming) and Timeline Therapy. I have found the so called use of forgiveness by most people is superficial and merely an attempt to feel superior by going through the motions of pardoning someone for the hurt they feel was caused them. Also too often this forgiveness is one-sided and actually develops victim mentality as the person fails to look within themselves to discover the accumulated guilt they have from unethical acts they committed. Forgiveness to be properly done must access higher levels of consciousness and thought so as to go to the core of the decisions made to undo the negative imprinting and replace them with a new positive framework.

During the course of our work Kathy attended my Course In Miracles class and Meditation Foundation Series and was really committed to learn new ways of living her life. She strongly desired to play tennis again and save her marriage as well as be a healthy role model for her children. Her son had almost died as a child and Kathy still carried tremendous guilt about that as well.

Kathy absorbed the deep work we were doing very well and thus became obvious in the new color in her face, spirited tone of voice and lightness in her step. She smiled more often now and told me the volatile relationship with her husband was improving daily and he had noticed a big change. She was using the principle she learned in class and in session and had connected to her higher powers of love and spirit in many delightful ways.

Within two months Kathy had reached a stable point so much so that she decided to fly out to the Midwest with her family to spend 
Thanksgiving with her mother and step father. This was a major breakthrough for Kathy as the years of anger and hatred had been peeled away and she was filled with love and compassion for her mother. She decided when she returned to spend each Thanksgiving there, Her marriage with her husband constantly improved and she was able to quickly iron out the bumps in the road and use what she learned to teach her husband new ways of communicating and handling things that came up. She also noticed that as she was filled with more and more peace her son became closer to her and actually started hugging and kissing her again. I explained to her how unresolved guilt and fear in her mind created negative waves in her energetic fields which were always being shared with her family and all those around her. As she purified her mind with the work we were doing she was changing her vibratory fields and resonating more love and understanding that would then be reflected back to her.

Within another month Kathy was back playing tennis and no longer was experiencing any thyroid imbalances. She now was deepening her meditation practice and leaning more tools in my advanced classes to help keep her on track as the occasional blips of agitation appeared. Kathy had realized her goals to be happy, save her marriage, play tennis again and have a balanced thyroid in about 4 months of committed work. Now she has a constant radiant smile and shares as much love as she can wherever she goes.

\section{Consciousness and health}

As we have seen in these two particular cases, different relationships were created in the mind. Each create different mental constructs; channels that allow life force energy to move in a more unobstructive internal directed manner. In our world consciousness comes in three forms that we concern ourselves with. It is important to get to the level of consciousness that most needs the movement or correction for the major shift in the body to occur. The body as condensed consciousness has its own tools to work with it. In the two cases discussed movement (transformation of spirit, love, feelings of aliveness) was able to be achieved at the biological level by working through the mind and emotions with small corrections at the physical level. For many people with thyroid problems a reverse approach may be needed as the body itself may have become stuck and frozen in a past moment of trauma reducing circulation. Others are caught in an inner loop that doesn't permit their system to reboot itself into the present.

\section{The different levels}

Just as $\mathrm{H} 2 \mathrm{O}$ can by either vapor, water or ice, depending on its level of condensation, the consciousness of life can be either physical, emotional, mental or spiritual. Regardless of the form or the level of condensation, it is still the same one substance, spirit, light, love, consciousness, creative intelligence, God, call it what you like). This allows us to understand that the ice can be melted and the water can then be evaporated (expanding its' space). So it goes with the life energy of the body, emotions or mind. If progress is not being made through mental or emotional means physical access is pursued. It is at these times that modalities such as bioenergetics, embodiment and bodynamics can be utilized. These processes activate the unconscious body/mind that is held in chronic tensions or as undeveloped areas, to help them return pulsation and aliveness once again. As repressed emotions are released, underlying thinking can be exposed and corrected. In this approach we embrace what a person was caught up in from back "then" which is locked in the body.

As you embrace what you resisted before to give yourself the opportunity to let go of your resistance and our fear you receive the ischemia in the vascular system. We erase our identification and attachments to the past as if it was the present and will be the future we replace it with like minded thinking that constructs a healthy circulation and flow in the biological system.

\section{Conclusion}

Until it is understood how we carry in our bodies and especially in our endocrine system the accumulated energy of our past, we can only at best obtain temporary relief form the resultant imbalances created. Through deep therapy work one can come to understand the role of forgiveness and trauma release combined with a retraining of the mind to relax and focus on the Authentic Self. When Deep Healing has occurred it returns ones life to a balanced and joyful state. To help in this process to deal with the many requests to help others around the world I have developed a Deep Healing Series to share the basic philosophies and techniques that I used with and taught Nina, Cynthia and Kathy. They are available on our website or at the Quantum Healing Center. Please see next page for a brief description of each CD Series.

P.S. The real names of the client's involved have been changed to respect their privacy, but all aspects of their case are as it occurred.

\section{Clear mind, open heart meditation}

In the ancient tradition millions have discovered an inner calm, mental clarity and enhanced focus to realize their highest potential and live life in a relaxed state of self awareness. The benefits of meditation have now been scientifically proven to demonstrate greater health, quicker recovery and anti-aging properties that extend life and your enjoyment of it. Perhaps most intriguing of all is that practicing meditators share their inner calmness with those around them creating an expanded field of well being to anyone in their vicinity. In this 12 CD Series Dr. Brian Sheen shares with you his research and experience of the past 35 years to enable you to restore your true Self and reconnect with your Source of existence to experience the joy of living in each and every moment.

\section{Building a foundation of miracle mindedness}

Building a Foundation of Miracle Mindedness is a breakthrough transformational series that lays the groundwork for living a life of miracles. A Course in Miracles is a powerful spiritual path that has helped millions worldwide shift their lives from one of anger, guilt and fear - to one of peacefulness, love and happiness. Popularized by such renowned authors like Marianne Williamson, Wayne Dyer and Dr. Gerald Jambolsky, A Course in Miracles helps train your mind to think in new ways to heal unresolved conflicts and grievances from your past and in your current life. This series of $11 \mathrm{CDs}$ is a unique expression of the many years of teaching by Quantum Healing Center Director and bestselling author Dr. Brian Sheen. His depth of comprehension is self-evident as he presents these powerful ideas in easy to understand and apply teachings that absorb the listener and provide in depth experiential processes to begin shifting your life to greater heights of happiness immediately. Cost $\$ 99$.

\section{The tools and techniques for peaceful living}

Peaceful living is a scientifically developed transformational series of effective steps developed by Dr. Brian Sheen, the Executive Director of The Quantum Healing Center after 30 years of research. This series works on physical, mental and emotional levels to reduce feelings of stress, anxiety and other related symptoms which can cause depression, insomnia and a weakened immune system. Vast and compelling research has verified how individuals experiencing 
unwanted stress and agitation can learn easy to understand techniques which, when applied provides greater health, mental clarity, emotional stability and creativity. People live longer and enjoy life more when they live comfortably within themselves and utilize the peaceful living strategies contained herein. Cost $\$ 89$.

Warning! Psychiatric Medications May Be Hazardous To Your Health!

Now more than ever the LIES of the drug companies are coming to light... "Pfizer" fined \$440million and GlaxoSmithKline sued for fraud by Attorney General New York!

These recordings expose the hidden truth about the numerous dangers of anti-depressants and the ADD/ADHD medications that your doctors prescribe. Most doctors are completely in the dark about these facts as they do not research the truth but instead depend upon the representations made by pharmaceutical reps from the drug companies and biased research reports bought and paid for by these same companies to promote their products! Cost \$20.

\section{The clear minded children's program TM}

Is a specially designed, experientially oriented educational program to help students on psychiatric medications become medication free? The program enables those not on medication to develop greater abilities to succeed and feel good about themselves and their families. This program is designed to be a first choice before choosing the potentially dangerous and addictive drugs like Ritalin, Adderal, Zoloft and Prozac etc...It is also designed to help those that are recently on medications get off them to build resources that make drugs unnecessary. This program acts as a training guide for teachers and parents to use these proven techniques in order to develop better connections and relationships that enhance learning, concentration, relaxation and choice abilities. Although developed with the ADD/ ADHD child as a primary focus--the program woks equally as well for children on anti-depressants or just not succeeding in family or school relationships as well as they would like. Of course using this program for a child who is already doing well, results in even greater enhancement and strengthening of their skills and allows them to become even more successful.

\section{Experiencing miracles through the body}

"The Secret to Lasting Change and Forgiveness Through A Course In Miracles.

A Course in Miracles is very clear "The body is the means by which God's son returns to sanity". The Course reminds us how "You have displaced your guilt to your body from your mind". As a serious student of the Course it is important to understand how our guilt is hidden from our awareness by repression into the unconscious mind/ body. Our current body image shows our true character; "The body is a symbol of what you think you are". Most get confused trying to use prayer or affirmations alone to correct their thinking but forget that the Course reminds us that "Correction must be introduced vertically from the bottom up". It's the hidden thoughts (unconsciousness) that create the real problem for until the roots of the wee/unloving thoughts are removed, the weed thoughts just keep growing back!

It was upon these premises that I have helped thousands of people improve their life conditions and why I have written books, recorded different CD series and started the Florida Institute of Complementary and Alternative Medicine (FICAM) so I can help educate others to find another way that doesn't numb them with toxic and addictive drugs.

\section{Biography}

Brian Sheen is a best-selling author, lecturer and is the Executive Director of the Florida Institute of Complementary and Alternative Medicine. Brian is a sought after expert and has appeared on Good Morning America, CNN, in USA Today and on hundreds of radio, TV and media outlets throughout the United States. Along with his transformative classes, he utilizes the most advanced techniques in modern therapy available today.

For the past forty five years he has trained with many of the leading professionals in this field such as Dr. Alexander Lowen, Dr. Frank Hladky, Dr. Richard Bandler, Dr. Brian Weiss, Credo Mutwa, Dr. Stanislov Grof, Swami Shyam, Ken Wapnick, Burt Hellinger and Carolyn Myss. He has spent time studying in Africa, India, Egypt, England and Mexico and through the world researching ancient wisdom and modern para- psychology. Brian specializes in Quantum Psychology, Neuro-Linguistic Programming, Clinical Hypnotherapy, psychoneuroimmunology, Shamanism as well as Past Life and childhood regressions. He received a $\mathrm{PhD}$ in Clinical Hypnotherapy from American Pacific University. Brian incorporates a wide-range of spiritual psychotherapies from A Course in Miracles and Shamanism.

\section{Acknowledgments}

None.

\section{Conflicts of interest}

Author declares there are no conflicts of interest.

\section{Funding}

None. 